\title{
C-ANCA-positive glomerulonephritis associated with subacute infective endocarditis caused by Bartonella infection
}

\author{
Min Jeong Kim", Ha Nee Jang ${ }^{1}$, Tae Won Lee ${ }^{1}$, Hyun Seop Cho ${ }^{1,2}$, Se-Ho Chang ${ }^{1,2}$, Hyun-Jung Kim ${ }^{1,2}$ \\ ${ }^{I}$ Department of Internal Medicine, Gyeongsang National University School of Medicine; ${ }^{2}$ Institute of Health Sciences, \\ Gyeongsang National University, Jinju, Korea
}

\begin{abstract}
Glomerulonephritis (GN) is sometimes associated with infective endocarditis (IE). Bartonella endocarditis is difficult to diagnose because it is rare and cannot be detected by blood culture. This is the first report of cytoplasmic anti-neutrophil cytoplasmic antibody-positive subacute endocarditis-associated GN caused by Bartonella infection in South Korea. A 67-year-old man was hospitalized due to azotemia. He complained of weight loss and anorexia for 6 months. A diagnosis of IE was made based upon echocardiographic detection of vegetations on the mitral and aortic valves and a Bartonella antibody titer of 1:2,048. Renal histology identified focal crescentic GN. Azotemia and proteinuria improved after doxycycline and rifampin treatment combining with steroid therapy.
\end{abstract}

Keywords: ANCA-associated glomerulonephritis; Bartonella; Infectious endocarditis

\section{INTRODUCTION}

Infective endocarditis (IE) is a life-threatening disease caused by an infection of the heart tissues. Isolation of the causative organism from blood culture is critical for accurate diagnosis and treatment. When culture results of three independent blood samples are negative, the putative diagnosis indicates blood culture-negative endocarditis (BCNE) [1]. The incidence of $\mathrm{BCNE}$ ranges from $5 \%$ to $15 \%$ in patients with endocarditis, depending on the country [2]. BCNE is associated with infection by a number of pathogens, including Granulicatella, Abiotrophia, HACEK organisms, Coxiella burnetii, and Bartonella spp. [3]. Diagnostic tests for BCNE include

Received: May 4, 2017, Revised: May 22, 2017 Accepted: June 1, 2017

Corresponding Author: Hyun-Jung Kim, Division of Nephrology, Department of Internal Medicine, Gyeongsang National University School of Medicine, 15 Jinju-daero 816beon-gil, Jinju 52727, Korea

Tel: +82-55-750-8875, Fax: +82-55-758-9122

E-mail: kimhjyh@naver.com special extended-culture techniques, molecular techniques, and histopathologic evaluation.

Approximately 40-50\% of IE cases have an associated kidney disease such as glomerulonephritis (GN) [4]. Crescentic $\mathrm{GN}$ is the most common renal pathology, which can be derived from anti-neutrophil cytoplasmic antibody (ANCA)-associated small-vessel vasculitis. The presence of ANCAs against proteinase-3 or myeloperoxidase is a key diagnostic marker [5].

Bartonella spp. were first described as a cause of endocarditis in 1993 [6]. Bacteria belonging to the Bartonella genus are facultative intracellular gram-negative rods that infect erythrocytes or endothelial cells [7]. Most reports of Bartonella IE have involved adult patients and more than $70 \%$ of cases were men [8]. The clinical manifestation of Bartonella IE is similar to that of other subacute IE [9]. A diagnosis of Bartonella IE, however, often requires diagnostic tests other than blood culture to identify the infectious agent (as is the case for other BCNE). In most cases, antibiotic treatment of Bartonella-caused IE is effective. If renal function deteriorates despite appropriate antibiotic therapy, other treatments

Copyright ( 12017 Yeungnam University College of Medicine

This is an Open Access article distributed under the terms of the Creative Commons Attribution Non-Commercial License (http://creativecommons.org/licenses/by-nc/4.0/) which permits unrestricted non-commercial use, distribution, and reproduction in any medium, provided the original work is properly cited. 
may be considered; these include corticosteroids, immunosuppressive agents, plasmapheresis, or valve replacement.

Bartonella IE is rare in South Korea [10], and kidney involvement has never been reported. This is the first report of cytoplasmic-ANCA (C-ANCA)-positive GN associated with subacute endocarditis caused by Bartonella infection in South Korea.

\section{CASE}

A 67-year-old man was transferred from a private clinic because of his azotemia. He complained of weight loss (7 $\mathrm{kg}$ ) and anorexia over the previous 6 months. He did not have any underlying disease nor had he undergone surgery in the previous 6 months. Physical examination at the time of admission revealed a blood pressure of $120 / 50 \mathrm{mmHg}$, a heart rate of 68 beats/min, a respiratory rate of 20 breaths/ min, and a body temperature of $36.4^{\circ} \mathrm{CC}$. Laboratory studies revealed a white blood cell count of $7,880 / \mathrm{mm}^{3}$, a hemoglobin level of $6.7 \mathrm{~g} / \mathrm{dL}$, and a platelet count of $206,000 / \mathrm{mm}^{3}$. His blood urea nitrogen level was elevated to $53.8 \mathrm{mg} / \mathrm{dL}$ and his serum creatinine $(\mathrm{sCr})$ was $4.35 \mathrm{mg} / \mathrm{dL}$. His serum potassium level was elevated to $7.0 \mathrm{mEq} / \mathrm{L}$. C-reactive protein was slightly elevated to $11.4 \mathrm{mg} / \mathrm{dL}$. Diagnostics indicated that his blood albumin/globulin $(\mathrm{A} / \mathrm{G})$ ratio was reversed (total protein was $9.1 \mathrm{~g} / \mathrm{dL}$, serum albumin was $2.8 \mathrm{~g} / \mathrm{dL}$ ). Urinalysis with microscopy revealed protein $(+)$ and red blood cell $>$ 100/high-power field. The protein-to-creatinine ratio in a spot urine test was $1.1 \mathrm{~g} / \mathrm{g}$. The level of serum C3 was decreased to $43.9 \mathrm{mg} / \mathrm{dL}$ (range, $90-180 \mathrm{mg} / \mathrm{mL}$ ), and the test for C-ANCA was positive. The size of the kidney was in the normal range on abdominal computed tomography.

Initially, we suspected multiple myeloma with kidney involvement due to $\mathrm{A} / \mathrm{G}$ reverse and azotemia. However, serum and urine protein electrophoresis with immunoelectrophoresis were consistent with polyclonal gammopathy. Transesophageal echocardiography revealed two vegetations on the mitral valve with moderate mitral regurgitation and one vegetation on the aortic valve with minimal aortal regurgitation (Fig. 1). At this time, we suspected subacute IE even though cultures of two blood samples were negative.

Renal histology revealed global sclerosis (4/28 glomeruli), mesangial proliferation $(8 / 28)$, fibrotic crescent formation (7/28), diffuse glomerular capillary walls thickened due to deposition of $\mathrm{C} 3$, immunoglobulin $\mathrm{M}$ (IgM), and C1q (detected by immunofluorescent staining), and electrodense subendothelial deposits (detected by electron microscopy) (Fig. 2).

We suspected GN associated with BCNE and so requested serological tests for Q fever, Legionella, and Bartonella from the Korean Centers for Disease Control and Prevention. We recommended assays for zoonotic organisms because the patient indicated that he had pets on his deer farm in the country.

The serological tests showed that the patient's Bartonella IgG antibody titer was elevated to 1:2048. Although he was subsequently treated with the antibiotics doxycycline and ri-
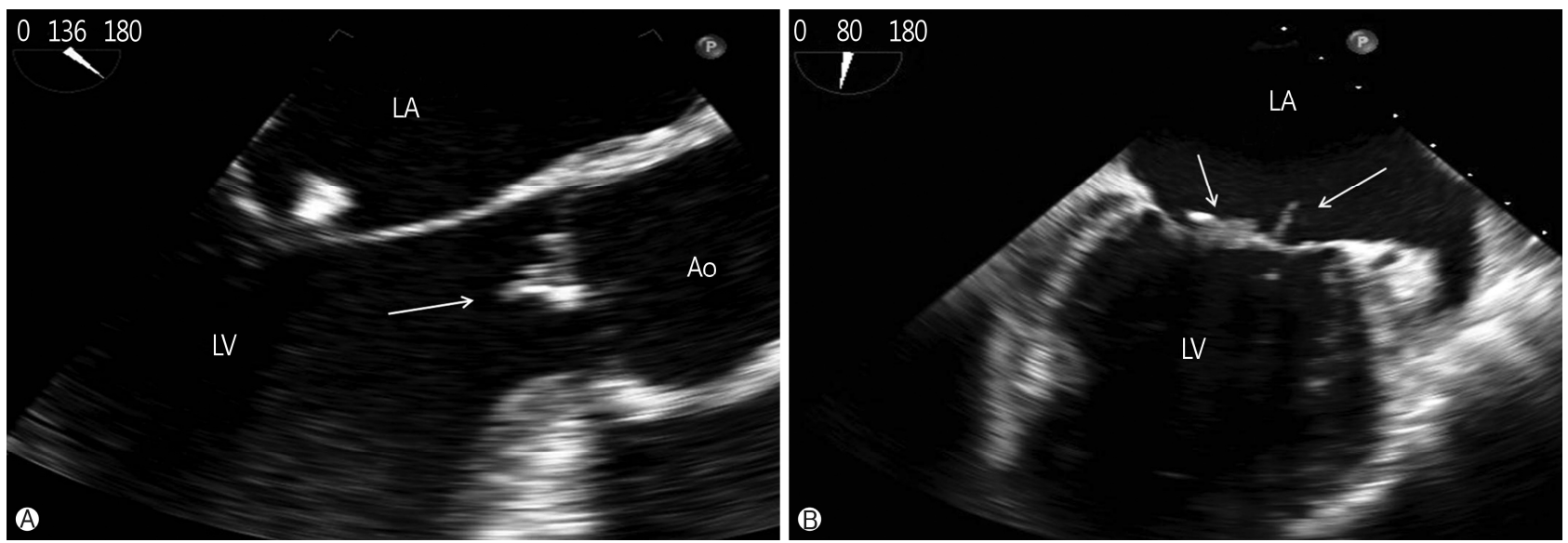

Fig. 1. Transesophageal echocardiographic findings. There was one echogenic mass $(9 \times 9 \mathrm{~mm}$; arrow $\mathrm{A})$, with mild $\mathrm{AR}$, on the aortic valve and two echogenic masses $(8 \times 5$ and $9 \times 9 \mathrm{~mm}$; arrows $\mathrm{B})$, with moderate $\mathrm{MR}$, on the mitral valve. $\mathrm{AR}$, aortic regurgitation; $\mathrm{MR}$, mitral regurgitation; LA, left atrium; LV, left ventricle; Ao, arota. 

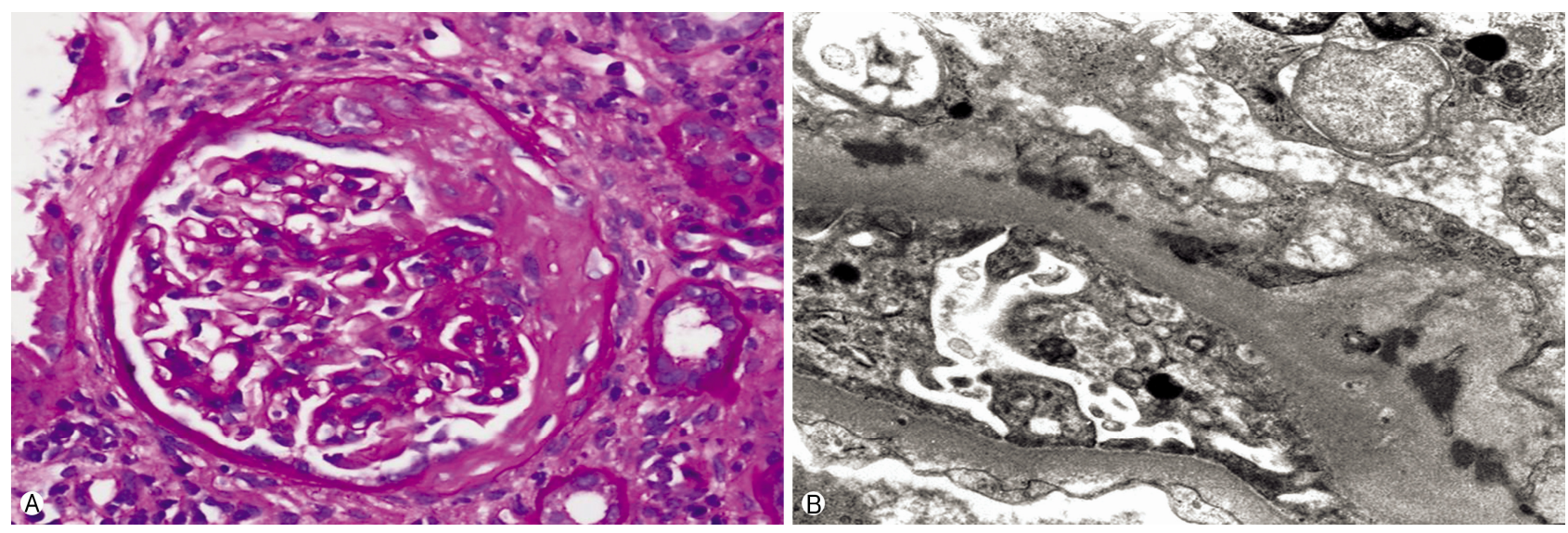

Fig. 2. Renal pathologic findings. (A) Periodic acid-Schiff staining under light microscopy $(\times 400)$. A glomerulus shows global mesangial expansion with mild thickening of the capillary wall and crescent formation. Tubulointerstitial lymphocytic infiltration and tubular atrophy are also present. (B) Electromicrograph showing some subendothelial electron dense deposits $(\times 10,000)$.

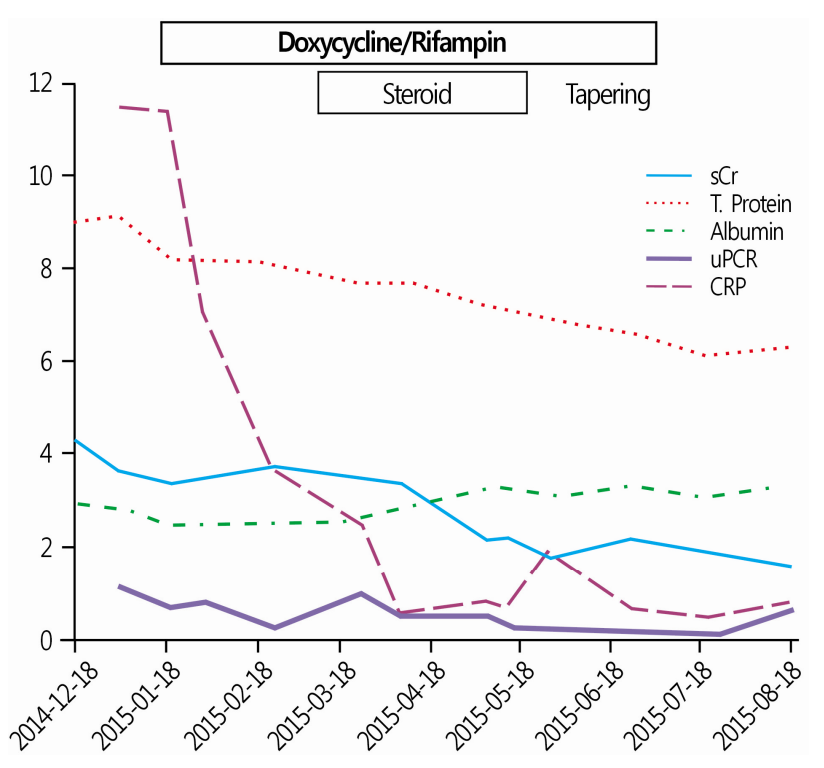

Fig. 3. Clinical course after admission. Serum creatinine and proteinuria improved after antibiotics were combined with steroid therapy. sCr, serum creatinine; CRP, C-reactive protein; uPCR, urine protein/creatinine ratio.

fampin for 8 weeks, his azotemia and proteinuria did not improve. After combining steroid therapy $(0.5 \mathrm{mg} / \mathrm{kg})$ with antibiotic treatment for another 6 weeks, his sCr improved to $2.10 \mathrm{mg} / \mathrm{dL}$, his proteinuria disappeared (Fig. 3), and his complement $\mathrm{C} 3$ level returned to normal. Follow-up transthoracic echocardiography after 5 months showed that one of two vegetations on the mitral valve disappeared and the other decreased slightly from $9.0 \times 9.0 \mathrm{~mm}$ to $9.3 \times 7.6 \mathrm{~mm}$ with mild mitral regurgitation. The size of vegetation on the aortic valve decreased markedly from $9.0 \times 9.0 \mathrm{~mm}$ to $5.3 \times 4.9 \mathrm{~mm}$. He currently receives out-patient support for chronic kidney disease.

\section{DISCUSSION}

The diagnosis of BCNE is difficult and uncommon in South Korea. Nevertheless, a rigorous approach is needed to identify the specific infectious causes of endocarditis and non-IE, including careful documentation of a case's history and asking the patient and family about contact with animals in the case of a potential zoonosis and joint, gastrointestinal, and neurological symptoms [11]. Our patient's self-reported history of animal contact was very helpful in our diagnosis.

Among the extra-cardiac manifestations associated with IE, renal involvement occurs in about 40-50\% of patients [12]. The causes of kidney disease include acute pyelonephritis, abscess formation from septic emboli, immune complex-mediated GN, ANCA-associated GN, and acute tubular necrosis or acute interstitial nephritis arising from renal toxicity caused by antibiotic treatment [12].

Renal biopsy is the only method of diagnosing IE-associated GN. Key histopathologic findings include emboli, interstitial nephritis, crescentic GN, immune complex-mediated GN, and acute tubular necrosis [13]. Our patient exhibited focal crescentic GN with focal mesangial GN.

In this case, a diagnosis of IE was made due to the echocardiographic detection of vegetations on the mitral and aortic 
valves, and a positive serologic test result for Bartonella. Some may argue that serologic testing is insufficient to diagnose bartonellosis because there is no definitive cut-off titer for diagnosis and because of the potential for cross-reaction with antibodies to Chlamydia spp. or Coxiella burnetii. However, Edouard et al. showed that an IgG titer greater than 1:800 (in an immunofluorescence antibody assay) or a positive western blot can be considered as major Duke criteria indicating Bartonella endocarditis [14].
The appropriate antibiotic treatment for Bartonella endocarditis is a 6-week course of amoxicillin, ceftriaxone, or doxycycline in combination with aminoglycosides for 2-4 weeks [15]. Surgical treatment is recommended if the condition is accompanied by heart failure, high embolic risk, and persistent sepsis [16]. Therefore, we did not remove the vegetations and initially prescribed doxycycline with rifampin rather than gentamicin due to the patient's azotemia.

There are four case reports of IE associated with GN in

Table 1. Characteristics of infective endocarditis with glomerulonephritis in Korea

\begin{tabular}{|c|c|c|c|c|c|}
\hline Case No. (year of report) & $1(1990)$ & $2(1999)$ & $3(2004)$ & $4(2009)$ & 5 (present) \\
\hline Sex/age & $\mathrm{M} / 53$ & $\mathrm{M} / 24$ & $\mathrm{M} / 28$ & $\mathrm{~F} / 59$ & $\mathrm{M} / 67$ \\
\hline Organism & No growth & S. viridans & S. sanguis & E. faecalis & Bartonella spp. \\
\hline \multicolumn{6}{|l|}{ Laboratory findings } \\
\hline CRP (mg/dL) & 9.9 & NR & 8.5 & 206.5 & 11.4 \\
\hline Total protein $(\mathrm{g} / \mathrm{dL})$ & 7.3 & 5.8 & 5.2 & 5.2 & 9.1 \\
\hline Serum albumin $(\mathrm{g} / \mathrm{dL})$ & 2.4 & 2.1 & 2.4 & 2.4 & 2.8 \\
\hline Serum $\mathrm{Cr}(\mathrm{mg} / \mathrm{dL})$ & 7.0 & 16.2 & 3.46 & 3.2 & 4.35 \\
\hline Proteinuria & $2.0 \mathrm{~g} /$ day & $(+++)$ & $1.5 \mathrm{~g} /$ day & $3.0 \mathrm{~g} /$ day & $1.1 \mathrm{~g} /$ day \\
\hline Serum $\operatorname{IgG}(\mathrm{mg} / \mathrm{dL})$ & $\mathrm{NR}$ & NR & $2,090.85$ & NR & $4,080.2$ \\
\hline Serum C3 & Decreased & Decreased & Decreased & Decreased & Decreased \\
\hline ANA titer & - & $1: 40$ & - & - & 1:40 \\
\hline ANCA & NR & NR & - & - & + \\
\hline Cryoglobulin & + & - & - & - & - \\
\hline Anti-GBM Ab & NR & NR & + & NR & - \\
\hline \multicolumn{6}{|l|}{ LM } \\
\hline Crescent & $29 \%$ & $100 \%$ & $21 \%$ & $54 \%$ & $25 \%$ \\
\hline Global sclerosis & $8 \%$ & - & $71 \%$ & - & $14 \%$ \\
\hline Segmental sclerosis & - & - & $7 \%$ & - & - \\
\hline Mesangial proliferation & Almost & - & - & - & $29 \%$ \\
\hline \multicolumn{6}{|l|}{ IF } \\
\hline $\mathrm{C} 3 / \mathrm{C} 1 \mathrm{q} / \mathrm{IgM}$ & $(+/+/+)$ & $(+/-/+)$ & $(+/+/+)$ & $(+/-/+)$ & $(+/+/+)$ \\
\hline Mesangial/capillary & $(+/+)$ & $(+/+)$ & $(+/-)$ & $(+/+)$ & $(-/+)$ \\
\hline \multicolumn{6}{|l|}{$\mathrm{EM}(\mathrm{EDD})$} \\
\hline Subepithelial & NR & + & - & $\mathrm{NR}$ & - \\
\hline Subendothelial & NR & + & + & NR & + \\
\hline Mesangial & NR & - & + & NR & + \\
\hline \multicolumn{6}{|l|}{ Treatment } \\
\hline Antibiotics & + & + & + & + & + \\
\hline Surgery & TVR & MVR & VSD repair & Not done & Not done \\
\hline Renal therapy & $\mathrm{HD}$ & Steroid+HD & PCX & Not done & Steroid \\
\hline Outcome & Died & CAPD & $\mathrm{CKD}$ & CKD & CKD \\
\hline
\end{tabular}

CRP, C-reactive protein; Cr, creatinine; IgG, imnunoglobulin G; ANA, anti-nuclear antibody; ANCA, anti-neutrophil cytoplasmic antibody; GBM Ab, glomerular basement membrane antibody; NR, not reported; LM, light microscopy; IF, immunofluorescence stain; EM, electron microscopy; EDD, electrodense deposits; TVR, tricuspid valve replacement; MV, mitral valve; VSD, ventricular septal defect; HD, hemodialysis, CAPD, continuous ambulatory peritoneal dialysis; PCX, plasma exchange; CKD, chronic kidney disease. 
Korea [17-20]. We summarized the characteristics of each in Table 1. Their clinical manifestations and course of infection were not different from cases reported elsewhere. Serological markers varied: cryoglobulin in case 1, anti-GBM antibody in case 3 [19], and ANCA in our case. Interestingly, all exhibited a reversed $\mathrm{A} / \mathrm{G}$ ratio, which initially led us to suspect multiple myeloma. We believe that the elevated IgG levels in cases 1 and 5 are related to polyclonal gammopathy and reveal the chronic inflammation associated with IE. All cases reported hypocomplementemia, azotemia, and mild proteinuria. The patient in case 1 died [17] and the other patients developed chronic kidney disease. The renal function of our patient was improving under treatment, but did not recover completely, although his proteinuria disappeared after combined steroid and antibiotic therapy. Follow-up echocardiography showed an improvement, but he still developed chronic kidney disease.

Diagnosis was delayed because the patient's chief complaint and his initial clinical findings were vague, and his condition was not rapidly progressive. Interestingly, the symptoms were very similar to those in a case reported by Van Haare Heijmeijer et al. [12]. However, this patient diagnosed to Bartonella IE lately after steroid and cyclophosphamide therapy for idiopathic ANCA-associated GN without antibiotics. They summarized the renal pathology and therapy for ten cases of Bartonella-caused endocarditis-associated GN. In most cases, their renal pathologies were either focal or diffuse crescentic GN. Moreover, as for our patient, seven of the patients displayed a positive ANCA result.

In conclusion, it is necessary to carefully evaluate the case history, conduct a thorough physical examination, and perform serologic tests to identify BCNE. In addition, if azotemia presents with proteinuria, a renal biopsy is considered to rule out GN-associated endocarditis. With proper diagnosis and early treatment, a patient may be able to recover renal function and experience a better clinical outcome.

\section{ACKNOWLEDGMENT}

The authors thank Dr. Oh-Hyun Cho and Dr. Dong Jun Park, Department of Internal Medicine and Dr. Dae Hyun Song, Department of Pathology, Gyeongsang National University Changwon Hospital, for assistance for this report.

\section{CONFLICT OF INTEREST}

Authors have no potential conflicts of interest to disclose.

\section{ORCID}

Min Jeong Kim, https://orcid.org/0000-0002-1677-7426

Ha Nee Jang, https://orcid.org/0000-0002-1402-931X

Tae Won Lee, https://orcid.org/0000-0003-1758-3217

Hyun Seop Cho, https://orcid.org/0000-0002-2103-9129

Se-Ho Chang, https://orcid.org/0000-0002-5278-0438

Hyun-Jung Kim, https://orcid.org/0000-0001-5883-4735

\section{REFERENCES}

1. Raoult D, Casalta JP, Richet H, Khan M, Bernit E, Rovery C, et al. Contribution of systematic serological testing in diagnosis of infective endocarditis. J Clin Microbiol 2005;43: 5238-42.

2. Fournier PE, Thuny F, Richet H, Lepidi H, Casalta JP, Arzouni JP, et al. Comprehensive diagnostic strategy for blood culture-negative endocarditis: a prospective study of 819 new cases. Clin Infect Dis 2010;51:131-40.

3. Houpikian P, Raoult D. Blood culture-negative endocarditis in a reference center: etiologic diagnosis of 348 cases. Medicine (Baltimore) 2005;84:162-73.

4. Khalighi MA, Nguyen S, Wiedeman JA, Palma Diaz MF. Bartonella endocarditis-associated glomerulonephritis: a case report and review of the literature. Am J Kidney Dis 2014;63: 1060-5.

5. Satake K, Ohsawa I, Kobayashi N, Osaki K, Toyoda H, Horikoshi S, et al. Three cases of PR3-ANCA positive subacute endocarditis caused by attenuated bacteria (Propionibacterium, Gemella, and Bartonella) complicated with kidney injury. Mod Rheumatol 2011;21:536-41.

6. Daly JS, Worthington MG, Brenner DJ, Moss CW, Hollis DG, Weyant RS, et al. Rochalimaea elizabethae sp. nov. isolated from a patient with endocarditis. J Clin Microbiol 1993;31:872-81.

7. Anderson BE, Neuman MA. Bartonella spp. as emerging human pathogens. Clin Microbiol Rev 1997;10:203-19.

8. Raoult D, Fournier PE, Vandenesch F, Mainardi JL, Eykyn SJ, Nash J, et al. Outcome and treatment of Bartonella endocarditis. Arch Intern Med 2003;163:226-30.

9. Durack DT, Lukes AS, Bright DK. New criteria for diagnosis of infective endocarditis: utilization of specific echocardiographic findings. Duke Endocarditis Service. Am J Med 1994; 96:200-9.

10. Lim MH, Chung DR, Kim WS, Park KS, Ki CS, Lee NY, et al. First case of Bartonella quintana endocarditis in Korea. J Korean Med Sci 2012;27:1433-5. 
11. Tattevin P, Watt G, Revest M, Arvieux C, Fournier PE. Update on blood culture-negative endocarditis. Med Mal Infect 2015;45:1-8.

12. Van Haare Heijmeijer S, Wilmes D, Aydin S, Clerckx C, Labrio la L. Necrotizing ANCA-positive glomerulonephritis secondary to culture-negative endocarditis. Case Rep Nephrol 2015;2015:649763.

13. Majumdar A, Chowdhary S, Ferreira MA, Hammond LA, Howie AJ, Lipkin GW, et al. Renal pathological findings in infective endocarditis. Nephrol Dial Transplant 2000;15: 1782-7.

14. Edouard S, Nabet C, Lepidi H, Fournier PE, Raoult D. Bartonella, a common cause of endocarditis: a report on 106 cases and review. J Clin Microbiol 2015;53:824-9.

15. Gould FK, Denning DW, Elliott TS, Foweraker J, Perry JD, Prendergast BD, et al. Guidelines for the diagnosis and antibiotic treatment of endocarditis in adults: a report of the Working Party of the British Society for Antimicrobial Chemotherapy. J Antimicrob Chemother 2012;67:269-89.

16. Baddour LM, Wilson WR, Bayer AS, Fowler VG Jr, Tleyjeh
IM, Rybak MJ, et al. Infective endocarditis in adults: diagnosis, antimicrobial therapy, and management of complications: a scientific statement for healthcare professionals from the American Heart Association. Circulation 2015;132:143586.

17. Lee KW, Chung TH, Park SB, Kim HC, Park KK, Lee SS. A case of diffuse proliferative glomerulonephritis in bacterial endocarditis. Korean J Nephrol 1990;9:427-33. Korean.

18. Lee JH, Ma KA, Kim HS, Shin KT, Kim MS, Suh YJ, et al. A case of crescentic glomerulonephritis associated with bacterial endocarditis. Korean J Nephrol 1999;18:820-4. Korean.

19. Han KH, Choi SW, Seong IW, Shin YT, Suh KS, Kwon GC, et al. Rapidly progressive glomerulonephritis associated with infective endocarditis: a dramatically improved case after plasmapheresis. Korean J Med 2004;67:73-7. Korean.

20. Kim JK, Lee YK, Oh SE, Cho JR, Noh JW, Nam ES, et al. Recovery from crescentic glomerulonephritis with bacterial endocarditis with antibiotics alone. Korean J Med 2009;76: 358-64. Korean. 